\title{
Formation of silyloxy-substituted pyrrolizidinones, indolizidinones and quinolizidinones via intramolecular cyclizations of $\alpha$-acylamino radicals with acylsilanes
}

\author{
Yeun-Min Tsai,* Hong-Chang Nieh, Jen-Sen Pan and Den-Dar Hsiao \\ Department of Chemistry, National Taiwan University, Taipei, Taiwan 106, Republic of China
}

$\alpha$-Acylamino radicals generated from acylsilanes $15,16,17$ and 21 cyclize to give good yields of silyloxy substituted pyrrolizidinones, indolizidinones and quinolizidinones.

Polyhydroxylated alkaloids such as swainsonine and castanospermine are interesting compounds that exhibit a wide variety of biological activities. ${ }^{1}$ Therefore, the synthesis of these natural products and their analogues is required for obvious pharmacological reasons. Recently, we developed a method using radical cyclizations of acylsilanes to give cycloalkyl silyl ethers. ${ }^{2}$ Now, we have employed this methodology in the construction of several polyhydroxy alkaloid skeletons.

As shown in Scheme 1, pyrrolizidinol $1(n=1)$, indolizidinols $\mathbf{1}(n=2)$ or $\mathbf{3}(n=1)$ and quinolizidinol $\mathbf{3}(n=2)$ could theoretically be synthesized via cyclizations of the corresponding $\alpha$-acylamino radicals $s^{3,4} 2$ and 4 . The required synthetic equivalents of $\mathbf{2}$ and $\mathbf{4}$ were synthesized as shown in Scheme 2 . 2-(Methyldiphenylsilyl)-1,3-dithiane $\mathbf{5}^{5}$ was alkylated with 2-bromoethyl or 3-bromopropyl tetrahydropyranyl ethers followed by deprotection to afford alcohols 6 and 7 . Mitsunobu coupling ${ }^{6}$ of succinimide with these alcohols using diisopropyl azodicarboxylate (DIAD) and triphenylphosphine gave imides 8 and 9 in good yields. However, a similar coupling reaction carried out with glutarimide was not successful. Tsunoda et al. ${ }^{7}$ recently reported a new reagent system for the Mitsunobu reaction applicable to nucleophiles with higher $\mathrm{p} K_{\mathrm{a}}$. Since glutarimide $\left(\mathrm{p} K_{\mathrm{a}}=11.43\right)^{8}$ is less acidic than succinimide $\left(\mathrm{p} K_{\mathrm{a}}=9.62\right),{ }^{9}$ we therefore applied Tsunoda's method using $1,1^{\prime}$-(azodicarbonyl)dipiperidine (ADDP) and tributylphosphine as the reagents for Mitsunobu coupling and gained<smiles>OC1CCCN2C[C@H](O)[C@H](O)C12</smiles>

swainsonine

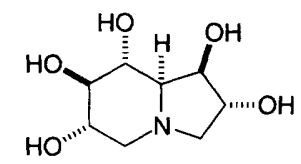

castanospermine

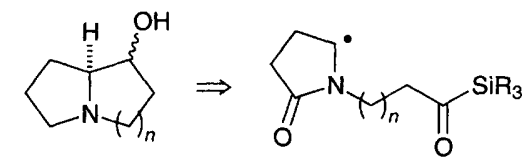

1

2

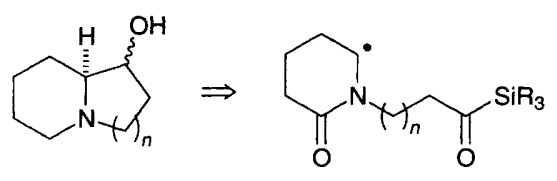

3 4

$n=1$ or 2

Scheme 1 successfully imide $\mathbf{1 0}$ in $70 \%$ yield from glutarimide. In contrast, imide 11 was still unattainable via this route.

Imides 8-10 were reduced with sodium borohydride according to Hubert et al., ${ }^{10}$ and the resulting crude alcohols were converted to the corresponding methyl ethers 12-14 by stirring with a catalytic amount of acid in methanol. Hydrolysis of the dithiane moiety was conducted using $\left(\mathrm{CF}_{3} \mathrm{CO}_{2}\right) \mathrm{IPh} .{ }^{11}$ The resulting crude acylsilanes ${ }^{12}$ were mixed with neat thiophenol in the presence of a catalytic amount of camphorsulfonic acid (CSA) to give the thioethers 15-17.4

In order to synthesize 11, we adopted a different approach. Mitsunobu coupling 6 of 6 with phthalimide gave imide 18 in high yield (Scheme 3 ). Imide 18 reacted with hydrazine and released the crude amine 19 which was subsequently treated with glutaric anhydride to give an amide acid. The resulting amide acid was cyclized in acetic anhydride to afford $11(84 \%$ from 18). In principle, this approach should be applicable to the synthesis of imides 8-10. Preparation of 21 was accomplished from 11 in $71 \%$ yield using the methods described previously.

The cyclizations of acylsilanes 15, 16, 17 and 21 were carried out with tributyltin hydride in refluxing benzene, and the results were shown in Table 1. In the case of 15 (entry 1), the cyclization was the least efficient. Reduction product $\mathbf{2 6}$, in which the acylsilane moiety was also reduced by tributyltin hydride, was present in $18 \%$ yield. In our model studies, ${ }^{13}$ 1,5-cyclizations were more efficient than 1,6-cyclizations. We believe that the cyclization of $\mathbf{1 5}$ was hampered by the strain imposed by the pre-existing five-membered ring. In compari-
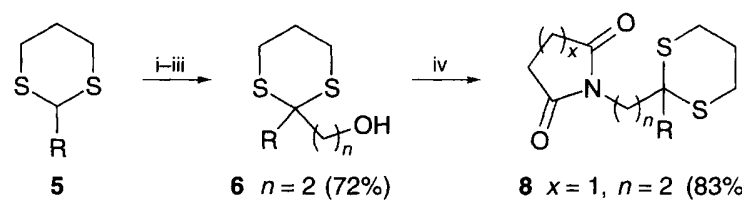

$7 n=3(92 \%)$

$8 x=1, n=2(83 \%)$

$9 x=1, n=3(91 \%)$

$10 x=2, n=3(70 \%)$

$11 x=2, n=2$

$\downarrow v$, iii<smiles>[R]C(=O)N1C(=O)CCCC1(C)[18F]</smiles><smiles></smiles>

$15 n=2(70 \%)$

$16 n=3(72 \%)$

$\mathrm{R}=\mathrm{SiPh}_{2} \mathrm{Me}$<smiles></smiles>

$12 x=1, n=2(98 \%)$

$13 x=1, n=3(90 \%)$

$14 x=2, n=3(90 \%)$

Scheme 2 Reagents and conditions: i, $\mathrm{BuLi}$; ii, $\mathrm{Br}\left(\mathrm{CH}_{2}\right)_{n} \mathrm{OTHP}$; iii, TsOH (cat), $\mathrm{MeOH}$; iv, DIAD, $\mathrm{Ph}_{3} \mathrm{P}$, succinimide, or ADDP, $\mathrm{Bu}_{3} \mathrm{P}$, glutarimide; $\mathrm{v}$, $\mathrm{NaBH}_{4}, \mathrm{HCl}-\mathrm{EtOH}$; vi, $\left(\mathrm{CF}_{3} \mathrm{CO}_{2}\right)_{2} \mathrm{IPh}, \mathrm{NaHCO}_{3}, \mathrm{MeCN}, \mathrm{H}_{2} \mathrm{O}$; vii, CSA (cat), $\mathrm{PhSH}$ (1 equiv.) 
son, acylsilane 21 (entry 3) cyclized very efficiently to give silyloxyindolizidinones $\mathbf{2 8}$ and $\mathbf{3 0}$ in a total of $82 \%$ yield. Silyloxyindolizidinones $23(63 \%)$ and $25(16 \%)$ were also obtained from 16 (entry 2), as was a small amount of reduction product 27. Silyloxyquinolizidinones $29(57 \%)$ and $31(15 \%)$ were isolated from the cyclization of 17 (entry 4). Only a trace amount of reduction product was observed, which was not fully characterized.

To determine the stereochemistry of the cyclization products, we performed NOE experiments on 24 and $\mathbf{3 0}$. In the case of $\mathbf{2 4}$ irradiation of $\mathrm{H}^{1}$ at $\delta 4.15(\mathrm{q}, J 3.0 \mathrm{~Hz}, 1 \mathrm{H})$ resulted in a $7.7 \%$<smiles>[R]C1(CCN)SCCCS1</smiles>
$18(97 \%)$

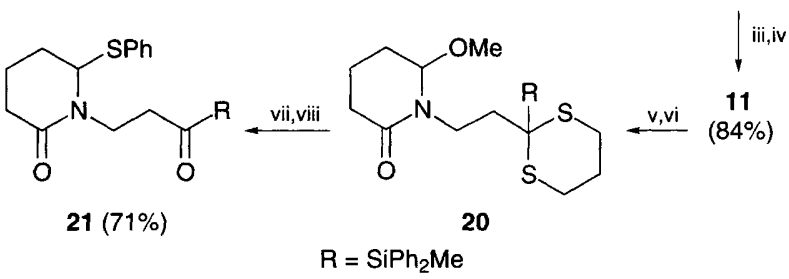

Scheme 3 Reagents and conditions: $\mathrm{i}, \mathrm{DIAD}, \mathrm{Ph}_{3} \mathrm{P}$, phthalimide; ii, hydrazine, $\mathrm{MeOH}, \mathrm{THF}, 50-60{ }^{\circ} \mathrm{C}$; iii, glutaric anhydride; iv, $\mathrm{Ac}_{2} \mathrm{O}$, $\mathrm{NaOAc}, 100-120{ }^{\circ} \mathrm{C}$; v, $\mathrm{NaBH}_{4}, \mathrm{HCl}-\mathrm{EtOH}$; vi, CSA (cat), $\mathrm{MeOH}$; vii, $\left(\mathrm{CF}_{3} \mathrm{CO}_{2}\right)_{2} \mathrm{IPh}, \mathrm{NaHCO}_{3}, \mathrm{MeCN}, \mathrm{H}_{2} \mathrm{O}$; viii, $\mathrm{CSA}$ (cat), $\mathrm{PhSH}$ (1 equiv.)

Table 1 Radical cyclizations of acylsilanes $15,16,17$ and $21^{a}$

\begin{tabular}{llll}
\hline Entry & $\begin{array}{l}\text { Starting } \\
\text { material }\end{array}$ & Product (yield, \%) & exo:endo \\
\hline $1^{b}$ & $\mathbf{1 5}$ & $\mathbf{2 2}(34), \mathbf{2 4}(18), \mathbf{2 6}(18)$ & 1.9 \\
$2^{c}$ & $\mathbf{1 6}$ & $\mathbf{2 3}(63), \mathbf{2 5}(16), \mathbf{2 7}(6)$ & 3.9 \\
$3^{c}$ & $\mathbf{2 1}$ & $\mathbf{2 8}(58), \mathbf{3 0}(23)$ & 2.5 \\
$4^{c . d}$ & $\mathbf{1 7}$ & $\mathbf{2 9}(57), \mathbf{3 1}(15)$ & 3.8 \\
\hline
\end{tabular}

$a$ To a refluxing solution of the acylsilane $(0.1 \mathrm{M}$ in benzene) was added a solution of tributyltin hydride ( 1.5 equiv.; $0.1 \mathrm{~m}$ in benzene) and AIBN ( 0.1 equiv.) over a period of $1.5 \mathrm{~h}$. ${ }^{b}$ Calculated via high-performance liquid chromatography. ${ }^{c}$ Isolation yields. ${ }^{d}$ Trace amount of reduction product was observed.

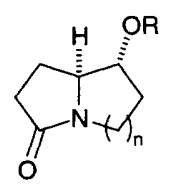

$22 n=1$

$23 n=2$<smiles>O=C1CCC[C@H]2[C@H](O)CCN12</smiles>

$28 n=1$

$29 n=2$

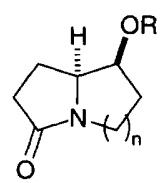

$24 n=1$

$25 n=2$<smiles>O=C1CCC[C@H]2CNCCN12</smiles>

$30 n=1$

$31 n=2$

$\mathrm{R}=\mathrm{SiPh}_{2} \mathrm{Me}$

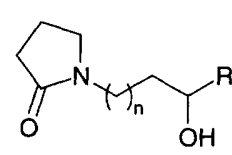

$26 n=1$

$27 n=2$

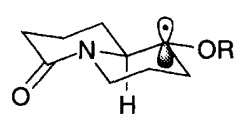

32 enhancement of the bridgehead hydrogen $\left(\mathrm{H}^{7 \mathrm{a}}\right)$ signal at $\delta 3.79$ (ddd, $J 8.0,6.0,3.0 \mathrm{~Hz}, 1 \mathrm{H}$ ). For 30, irradiation at $\delta 4.30$ (td, $J 3.0,1.6 \mathrm{~Hz}, 1 \mathrm{H}, \mathrm{H}^{1}$ ) resulted in a $14 \%$ enhancement at $\delta$ 3.31-3.41 (m, $\left.1 \mathrm{H}, \mathrm{H}^{8 \mathrm{a}}\right)$. These experiments indicated the cisrelationship between the two hydrogens. The desilylated alcohol analogue of $\mathbf{2 3}$ was identical to data reported by MartínLópez and Bermejo-González. ${ }^{14}$ In 29, the $\mathrm{H}^{1}$ absorption showed as a td $(J 9.4,4.4 \mathrm{~Hz})$ at $\delta 3.41$. The coupling pattern indicated that $\mathrm{H}^{1}$ of 29 was in the axial position, in support of its trans-relationship with $\mathrm{H}^{9 \mathrm{a}}$. In contrast, $\mathrm{H}^{1}$ of 31 appeared as a narrow broad signlet at $\delta 3.79$, an indication that it was situated in the equatorial position.

In the cyclization process, $\alpha$-acylamino radicals are generated and add to the acylsilane. The resulting $\beta$-silyl alkoxy radicals undergo radical-Brook rearrangement ${ }^{15}$ to give $\alpha$ silyloxy radicals, such as 32. It is well known that cyclohexyl radicals preferentially abstract hydrogen atom from the axial position. ${ }^{16}$ This led to the $4: 1$ exo-endo product ratio observed in entries 2 and 4 (Table 1). In the case of cyclopentyl radicals, the selectivity dropped due to the flexibility of the cyclopentane ring, as in entries 1 and 3.

In summary, we developed a general strategy based on radical cyclizations of acylsilanes to prepare silyl ethers of hydoxypyrrolizidinone, hydroxyquinolizidinone and two types of hydroxyindolizidinones. These cyclization products should prove useful for the synthesis of more complicated alkaloids. ${ }^{13,17}$

We thank the National Science Council of the Republic of China for financial support.

\section{References}

1 M. Naruse, S. Aoyagi and C. Kibayashi, J. Org. Chem., 1994, 59, 1358; K. Burgess and I. Henderson, Tetrahedron, 1992, 48, 4045; A. Brandi, S. Cicchi, F. M. Cordero, R. Frignoli, A. Goti, S. Picasso and P. Vogel, J. Org. Chem., 1995, 60, 6806 and references cited therein.

2 Y.-M. Tsai and C.-D. Cherng, Tetrahedron Lett., 1991, 32, 3515; Y.-M. Tsai and S.-Y. Chang, J. Chem. Soc., Chem. Commun., 1995, 981.

3 M. D. Bachi, F. Frolow and C. Hoornaert, J. Org. Chem., 1983, 48, 1841 .

4 J. M. Dener, D. J. Hart and S. Ramesh, J. Org. Chem., 1988, 53, 6022; D. A. Burnett, J.-K. Choi, D. J. Hart and Y.-M. Tsai, J. Am. Chem. Soc., 1984, 106, 8201; D. J. Hart and Y.-M. Tsai, J. Am. Chem. Soc., 1984, 106, 8209 .

5 A. G. Brook, J. M. Duff, P. F. Jones and N. R. Davis, J. Am. Chem. Soc., $1967,89,431$; E. J. Corey, D. Seebach and R. Freedman, J. Am. Chem. Soc., 1967, 89, 434.

6 O. Mitsunobu, Synthesis, 1981, 1.

7 T. Tsunoda, Y. Yamamiya and S. Itô, Tetrahedron Lett., 1993, 34, 1639.

8 G. Schwarzenbach and K. Lutz, Helv. Chim. Acta, 1940, 23, 1162.

9 H. F. Walton and A. A. Schilt, J. Am. Chem. Soc., 1952, 74, 4995.

10 J. C. Hubert, J. B. P. A. Wijnberg and W. N. Speckamp, Tetrahedron, $1975,31,1437$.

11 G. Stork and K. Zhao, Tetrahedron Lett., 1989, 30, 287.

12 Y.-M. Tsai, H.-C. Nieh and C.-D. Cherng, J. Org. Chem., 1992, 57, 7010.

13 Y.-M. Tsai, K.-H. Tang and W.-T. Jiaang, Tetrahedron Lett., 1993, 34, 1303.

14 M. J. Martín-López and F. Bermejo-González, Tetrahedron Lett., 1994 , 35, 8843 .

15 J. C. Dalton and R. A. Borque, J. Am. Chem. Soc., 1981, 103, 699; J. M. Harris, I. MacInnes, J. C. Walton and B. Maillard, J. Organomet. Chem., 1991, 403, C25.

16 B. Giese, Angew. Chem., Int. Ed. Engl., 1989, 28, 969.

17 H. Takahata, Y. Banba and T. Momose, Tetrahedron, 1991, 47, 7635; T. Oishi, T. Iwakuma, M. Hirama and S. Itô, Synlett, 1995, 404.

Received, 13th August 1996; Com. 6/05686E 